\title{
Effects of Repeated Alcohol Deprivations on Operant Ethanol Self-Administration by Alcohol-Preferring (P) Rats
}

\author{
Zachary A Rodd",', Richard L Bell', Kelly A Kuc', James M Murphy', , Lawrence Lumeng ${ }^{2,4}$, Ting-Kai Li ${ }^{2,5}$ and \\ William J McBride ${ }^{1,5}$ \\ 'Department of Psychiatry, Institute of Psychiatric Research, Indiana University School of Medicine, Indianapolis, IN 46202, USA; ${ }^{2}$ Department of \\ Medicine, Institute of Psychiatric Research, Indiana University School of Medicine, Indianapolis, IN 46202, USA; 'Department of Psychology, \\ Purdue School of Science, Indiana University-Purdue University at Indianapolis, Indianapolis, IN 46202, USA; ${ }^{4}$ VA Medical Center, Indianapolis, IN \\ 46202, USA; ${ }^{5}$ Department of Biochemistry, Institute of Psychiatric Research, Indiana University School of Medicine, Indianapolis, IN 46202, USA
}

\begin{abstract}
We reported that repeated alcohol deprivations prolonged the expression of an alcohol-deprivation effect (ADE) under 24-h freechoice alcohol-drinking access and that the duration of the initial deprivation period had a positive effect of prolonging the duration of the ADE. In the present study, operant techniques (including progressive ratio measures) were used to examine the effects of initial deprivation length and number of deprivation cycles on the magnitude and duration of the ADE in alcohol-preferring $(P)$ rats to test the hypothesis that repeated deprivations can increase the reinforcing effects of ethanol $(E T O H)$. Adult male $P$ rats were trained in two-lever operant chambers to self-administer I5\% ETOH (v/v) on a fixed-ratio 5 (FR-5) and water on a FR-I schedule of reinforcement in daily Ih sessions. Following 6 weeks of daily I-h sessions, the P rats were randomly assigned to one of four groups ( $n=10 /$ group): nondeprived or deprived of alcohol for 2, 5, or 8 weeks. Following this initial period, the deprived groups were given 15\% ETOH again in the operant chambers for a 2 -week period, following which they were deprived again for 2 weeks (all three deprived groups). Following the fourth deprivation, the rats underwent a progressive ratio test to determine the breakpoints (FR values) for the nondeprived and the deprived groups. Repeated deprivations increased both the magnitude and duration of the ADE as indicated by increased responding on the $\mathrm{ETOH}$ lever. However, the length of the initial deprivation had little effect on expression of the ADE except following the first deprivation, where an ADE was not observed for the 8-week group. Breakpoint values for responding on the ETOH lever for all three deprived groups were two-fold higher than the value for the nondeprived group. The results suggest that repeated cycles of alcohol deprivation and alcohol access increased the reinforcing effects of $\mathrm{ETOH}$ in the $\mathrm{P}$ rats.

Neuropsychopharmacology (2003) 28, 1614-1621, advance online publication, I I June 2003; doi: I 0.1038/sj.npp. I 3002 I 4
\end{abstract}

Keywords: alcohol-deprivation effect; operant self-administration; alcohol-preferring P rats; repeated deprivations; progressive ratio

\section{INTRODUCTION}

The alcohol deprivation effect (ADE) is defined as a temporary increase in the voluntary intake of ethanol (ETOH) solutions and the ratio of ETOH/total fluid intake over baseline drinking conditions, when ETOH is reinstated following a period of alcohol deprivation (Sinclair and Senter, 1967, 1968). The ADE has been hypothesized to be an animal model of alcohol craving (Heyser et al, 1997; Sinclair and $\mathrm{Li}, 1989$ ) and has been utilized to examine the efficacy of pharmacological agents to prevent relapse

\footnotetext{
*Correspondence: Dr ZA Rodd-Henricks, Institute of Psychiatric Research, Indiana University School of Medicine, 79I Union Dr, Indianapolis, IN 46202-4887 USA. Tel: + I 317278 3003, Fax: + I 317274 365, E-mail: zrodd@iupui.edu

Received 20 September 2002; revised 06 February 2003; accepted 21 March 2003

Online publication: 23 April 2003 at http://www.acnp.org/citations/ Npp04200347/default.pdf
}

drinking (Heyser et al, 1998; Kornet et al, 1991; Spanagel and Zieglgansberger, 1997).

The ADE phenomenon has been studied in several lines of rats. Alcohol-preferring $(\mathrm{P})$ rats given continuous access to free-choice ETOH for approximately 1 month demonstrated an ADE after intervals of $12 \mathrm{~h}$ or 1 week (Sinclair and $\mathrm{Li}$, 1989). In addition, with daily 4 -h operant scheduled access sessions, $\mathrm{P}$ rats exhibited an increase in responding for ETOH compared to baseline after 2 weeks of alcohol deprivation (McKinzie et al, 1998). In contrast, other rat lines that were selectively bred for high alcohol consumption did not exhibit an ADE after the initial deprivation following 24-h free-choice drinking conditions. The Alko Alcohol accepting (AA) line of rats does not show an ADE with deprivation periods that exceed 5 days (Sinclair and $\mathrm{Li}$, 1989; Sinclair and Tiihonen, 1988). The Sardinian alcoholpreferring (sP) rat did not display an ADE during the initial 24-h period of ETOH re-exposure after being alcohol deprived for periods between 3 and 30 days (Agabio et al, 
2000). In addition, both replicate lines of the high-alcoholdrinking (HAD) rats did not exhibit an ADE after a 2-week deprivation period that followed 6 weeks of continuous free-choice alcohol drinking (Rodd-Henricks et al, 2000a). Thus, it appears that the $\mathrm{P}$ rat may be unique among the selected lines in demonstrating an ADE after a single prolonged deprivation, which followed chronic 24-h freechoice alcohol drinking.

Although most animal studies examining the ADE have employed a single deprivation period, research has shown that the drinking patterns of human alcoholics are segmented by multiple periods of abstinence and intake (Burish et al, 1981; Hilbrom, 1990; McMillen, 1997). Therefore, the effects of multiple deprivations on expression of an ADE were examined in P and HAD rats under 24-h free-choice alcohol drinking conditions. We reported that expression of an $\mathrm{ADE}$ in the selectively bred $\mathrm{P}$ and $\mathrm{HAD}$ lines of rats is modified by exposure to repeated cycles of alcohol availability and deprivation (Rodd-Henricks et al, $2000 \mathrm{a}, \mathrm{b}$ ). In P rats given 24-h free-choice between 10\% (v/ v) ETOH and water, repeated deprivations prolonged the expression of the ADE, but did not alter its magnitude (Rodd-Henricks et al, 2000b). In the HAD replicate lines, the expression of an ADE was dependent upon repeated deprivations, and in the HAD-2 line, the $\mathrm{ADE}$ was also prolonged with repeated deprivations (Rodd-Henricks et al, 2000a). The increase in duration of the ADE in the $\mathrm{P}$ rat with repeated deprivations, and the expression of an ADE in HAD rats only after repeated deprivations suggested that alterations in the reinforcing properties of ETOH may be taking place with repeated deprivation cycles.

One approach toward examining the effects of repeated deprivations on the reinforcing properties of ETOH is with the use of operant techniques. Alterations in the amount of work a subject will do to obtain a reinforcement (in this case ETOH) can be inferred to indicate changes in the intrinsic reward of the reinforcer (Hodos, 1961). However, the effects of repeated deprivations on operant responding for ETOH have not been studied thus far.

The P line of rats satisfies the criteria proposed by Cicero (1979) for an animal model of alcoholism. Evidence (reviewed in McBride and Li, 1998; Murphy et al, 2002) indicates that this line of rats voluntarily consumes ETOH for its postingestion pharmacological effects, attains blood alcohol levels in the range of $50-200 \mathrm{mg} \%$, will work to obtain $\mathrm{ETOH}$, and develops tolerance and dependence through free-choice alcohol drinking. In addition, the $\mathrm{P}$ rat demonstrates relapse alcohol drinking after a single deprivation under both 24 -h free-choice drinking and 4-h operant access conditions. Therefore, the $\mathrm{P}$ rat was selected for this study to examine the effects of repeated deprivation cycles (which more closely mimic the human condition) on the reinforcing properties of ETOH.

The objective of the present study was to extend the alcohol-drinking study with $\mathrm{P}$ rats (Rodd-Henricks et al, $2000 \mathrm{~b}$ ) and use operant techniques to examine the effects of initial deprivation length and repeated cycles of ETOH deprivation on the reinforcing properties of ETOH. The hypothesis to be tested is that repeated cycles of ETOH drinking and long-term deprivation will increase the rewarding effects of alcohol, as indicated by a marked increase in responding for ETOH, and hence greater ETOH consumption. Additionally, following the last deprivation period, the reinforcing properties of ETOH were assessed quantitatively through the use of a progressive ratio paradigm (Roberts et al, 1989) to test the hypothesis that the reinforcing properties of ETOH are enhanced following repeated cycles of alcohol deprivation.

\section{METHODS}

\section{Animals}

Adult male $\mathrm{P}$ rats from the 46th-48th generation weighing $250-325 \mathrm{~g}$ at the start of the experiment were used. Rats were maintained on a 12 -h reversed light-dark cycle (lights off at $0900 \mathrm{~h}$ ). Food and water were available ad libitum throughout the experiment, except during operant testing. The animals used in these experiments were maintained in facilities fully accredited by the Association for the Assessment and Accreditation of Laboratory Animal Care (AAALAC). All research protocols were approved by the institutional animal care and use committee and are in accordance with the guidelines of the Institutional Care and Use Committee of the National Institute on Drug Abuse, National Institutes of Health, and the Guide for the Care and Use of Laboratory Animals (Institute of Laboratory Animal Resources, Commission on Life Sciences, National Research Council 1996).

Operant apparatus. Alcohol self-administration was conducted in standard two-lever experimental chambers (Coulbourn Instruments) contained within ventilated, sound-attenuated enclosures. Two operant levers located on the same wall were placed $15 \mathrm{~cm}$ above a grid floor and $13 \mathrm{~cm}$ apart. Directly beneath each lever was a trough through which a dipper cup $(0.1 \mathrm{ml})$ was raised to deliver response-contingent fluid. Upon a reinforced response, a small light cue was illuminated in the drinking trough during the 4-s dipper cup access. A personal computer controlled all operant chamber functions, and recorded lever responses and dipper presentations.

Operant training and repeated cycles of deprivation and ETOH access. Initially, $\mathrm{P}$ rats were given continuous access to $15 \%(\mathrm{v} / \mathrm{v})$ ETOH as their sole fluid for 2 days, followed by 24-h free-choice access to ETOH and water for 2 weeks. The rats were then given daily 4 -h access sessions to ETOH (with water always available) for another 3 weeks. During the last week of scheduled ETOH access in the home cage, rats were trained to respond for saccharin $(0.0125 \% \mathrm{~g} / \mathrm{v})$. After each operant session with saccharin, rats were returned to their home cage, where scheduled access to ETOH began for the day. After the animals had been trained to respond for saccharin, ETOH (15\%) was substituted for saccharin and animals were trained over a 6-week period to respond for ETOH and water as concurrent reinforcers. Subsequent studies indicated that neither the home cage drinking nor the autoshaping with saccharin was necessary, because $\mathrm{P}$ rats readily learn to respond for $15 \%$ ETOH within four 90 min sessions without prior training or exposure to ETOH (Rodd-Henricks et al, 2002a, b).

Water was always reinforced on a fixed-ratio-1 (FR-1) schedule, whereas ETOH was gradually increased to an FR-5 
schedule. The response requirement on the ETOH lever was increased by two every other week (third week - FR3; fifth week-FR5) for a total of 6 weeks concurrent responding for ETOH and water. Levers associated with ETOH or water were counterbalanced among rats but remained constant for each animal. The daily 1-h operant sessions provided the only access to ETOH for the remainder of the study.

Following the initial 6-week operant period, rats were randomly assigned to one of four groups. Three groups of rats were initially deprived for 2,5 , or 8 weeks $(n=10 /$ group). During the deprivation period, rats were maintained in their home cage and were not given access to the experimental chambers. All rats were then re-exposed to the experimental chambers, and allowed to respond on a concurrent FR-5/FR-1 for ETOH vs water for 2 weeks. Following this re-exposure period, all previously deprived rats, regardless of initial deprivation length, were deprived of ETOH and access to the operant chamber for 2 weeks. This cycle of 2-week deprivation/2-week ETOH access was continued for four deprivation and three re-exposure periods. The fourth group (nondeprived; $n=10$ ) received daily 1-h operant sessions for an additional 17 weeks (thus matching the 5-week deprivation group for the duration of ETOH access). The concurrent FR-5/FR-1 schedule for 15\% ETOH $v s$ water was maintained during these operant sessions.

Progressive ratio. In the three deprived groups, following the fourth deprivation period, rats were assessed in a modified progressive ratio test to determine the effects of repeated deprivations on the breakpoint value. The nondeprived rats were tested under the progressive ratio procedure after 23 weeks of continual ETOH operant exposure. The response requirement in the progressive ratio was as follows: all rats began at an FR-2 schedule of reinforcement on the ETOH lever, and after three reinforcements (six lever presses), the schedule was increased by two to FR-4; after receiving another three reinforcements (12 lever presses), the schedule was increased by two to FR-6. This pattern of increasing the response requirement by two after each three reinforcements was continued until the rat did not meet the FR requirement within $7 \mathrm{~min}$. The lowest FR value that the rat could not attain was defined as the breakpoint. This progressive ratio schedule was selected in an attempt to balance the multiple factors involved in oral ETOH self-administration (i.e. slow delivery of the drug $(0.1 \mathrm{ml} /$ reinforcement), slow rate of absorption of ETOH, and the sedative effects of ETOH). Therefore, this progressive ratio paradigm was used in order to increase sufficiently the required workload before the sedative effects of ETOH began to interfere with operant performance. The water lever was maintained on an FR-1 throughout the progressive ratio paradigm.

Statistical analysis. Overall operant responding (60 min) data were analyzed with a mixed factorial ANOVA with a between-subject factor of group (initial deprivation length) and repeated measure of 'session' and 'cycle' when applicable. The baseline measure for the factor of 'day' was the average number of responses on the ETOH lever for the three sessions immediately prior to deprivation.
Operant responding data were also analyzed in 10-min blocks, which required the additional repeated measure of time. The progressive ratio data were analyzed with an ANOVA performed on the dependent measure of breakpoint (FR value) and total responses on the ETOH lever with a between-subject factor of group. Post hoc Tukey's b was performed to determine individual differences.

\section{RESULTS}

At the end of the 6-week period of operant access, there were no differences between any of the four groups with regard to responses/session on either the ETOH lever (Figures 1 and 2: $\mathrm{F}_{3,36}=1.5 ; p=0.23$ ) or water lever (water lever data for deprived groups not shown: range $16 \pm 3$ to $20 \pm 4$ responses/session; $\mathrm{F}_{3,36}=2.0 ; p=0.14$ ). For $\mathrm{P}$ rats in the nondeprived group, responding on the ETOH lever remained relatively constant throughout the course of the experiment (Figure 1). Analyzing the weekly averages for responses/session on the ETOH or water lever indicated that responding on each lever was fairly stable across the final 17 weeks of the experiment $\left(F^{\prime} s_{16,44}<1.25 ; p\right.$ 's $\left.>0.28\right)$. In general, the number of reinforcements obtained in $\mathrm{P}$ rats that were never deprived ranged from a weekly average of $49 \pm 4$ to $55 \pm 5$ dipper presentations/session.

\section{Responses/Session on ETOH Lever After a Single Deprivation}

Responding on the ETOH lever by the three deprived groups after the initial deprivation period (Figure 2) was significantly different from baseline levels (session; $\mathrm{F}_{5,135}=5.4 ; p<0.0001$ ), and there was a significant interaction between initial deprivation length and responses on the ETOH lever across sessions (session $\times$ group; $F_{10,135}=15.8$; $p<0.0001$ ). The interaction term was decomposed by examining ETOH lever responding at baseline and during the initial four re-exposure sessions separately for each deprived group (2-, 5-, or 8-week initial deprivation). The data indicated that for the 2-week group, after the first

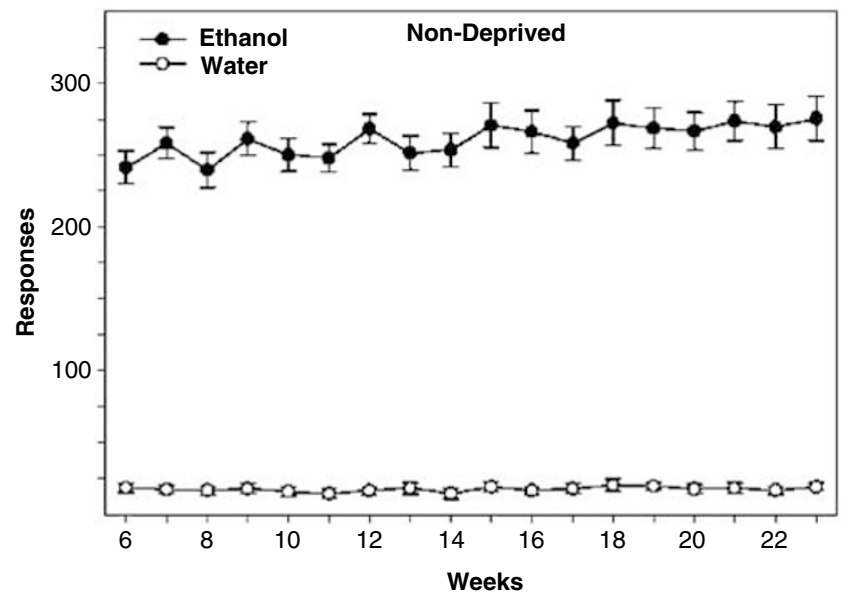

Figure I Mean $( \pm$ SEM) responses/session on the ethanol and water levers for $P$ rats $(n=10)$ in the nondeprived group given daily 60-min access to 15\% ethanol and water for 23 consecutive weeks. Responses on both the ethanol and water lever did not change significantly across sessions. 


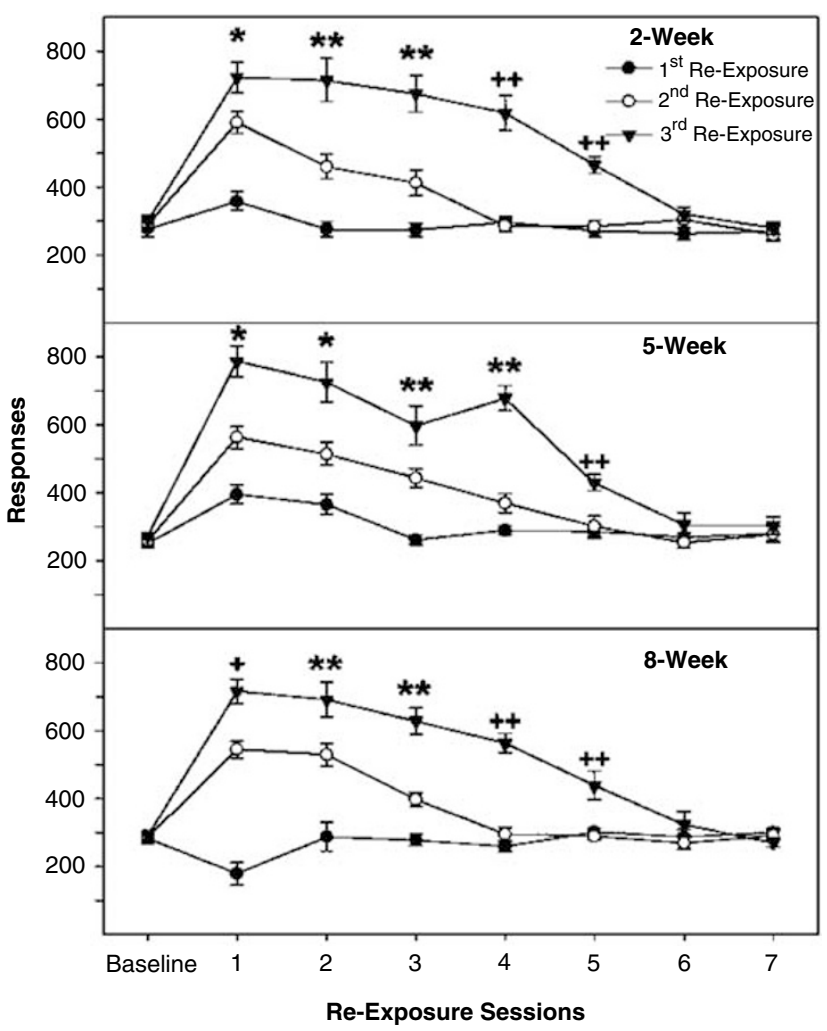

Figure 2 The mean ( \pm SEM) responses/session on the ethanol lever during 60-min access sessions by $P$ rats initially deprived of ethanol for 2,5 , or 8 weeks ( $n=10 /$ group), and then subjected to two additional cycles of 2 weeks of ethanol drinking and 2 weeks of deprivation (second and third reexposures). Baseline values are the average responses for each rat on the last 3 days prior to deprivation. $* 0<0.05$ (values for all three re-exposures greater than baseline and values for second and third re-exposures greater than first re-exposure, and third re-exposure greater than the second reexposure); ${ }^{+} p<0.05$ (values for the second and third re-exposure cycles greater than baseline and different from each other, and values for the first re-exposure less than baseline); ** $p<0.05$ (values for second and third reexposures greater than baseline and first re-exposure, and different from each other); ${ }^{++} p<0.05$ (values for third re-exposure greater than baseline, and first and second re-exposures).

deprivation, responding on the ETOH lever was significantly higher during the first session compared to baseline levels $\left(\mathrm{F}_{4,36}=14.3 ; p<0.0001\right.$; post hoc $\left.p<0.05\right)$. In the 5week group, after the first deprivation, responding on the ETOH lever was significantly higher during the first two sessions compared to baseline $\left(\mathrm{F}_{4,36}=24.9 ; p<0.0001\right.$; post hoc $p<0.05)$. In contrast, for rats in the 8-week group, after the first deprivation, responding on the ETOH lever was significantly reduced during the first re-exposure session compared to baseline responding $\left(\mathrm{F}_{4,36}=6.3 ; p=0.03\right.$; post hoc $p<0.05)$. Group differences were further indicated by individual ANOVAs performed on ETOH responding during each individual re-exposure session. During the first re-exposure session, there was a significant effect of group $\left(\mathrm{F}_{2,27}=19.3 ; p<0.0001\right)$, and post hoc comparisons indicated that responding in the 2 - and 5 -week groups was significantly higher than the 8-week group. The reinforcements obtained during the first re-exposure session by the 2 - and 5-week-deprived groups were increased from $55 \pm 4$ and $51 \pm 3$ to $72 \pm 5$ and $79 \pm 5$, respectively, following deprivation. Water responding (data not shown) was unaffected by the deprivation period in any of the three deprived groups, and remained at approximately $15 \pm 4$ responses/session.

\section{Responses on the ETOH Lever After the Second and Third Deprivations}

Responding on the ETOH lever for the three deprived groups returned to baseline levels by the end of each reexposure period (Figure 2; F's $s_{2,54}<1.36 ; p$ 's $>0.28$ ). However, after the second and third deprivations, responding on the ETOH lever was significantly increased during sessions 1-5 of re-exposure (cycle $-\mathrm{F}_{2,54}=129.9$; session $-\mathrm{F}_{7,189}=200.9$; cycle $\times$ session $-\mathrm{F}_{14,378}=71.1$; cycle $\times$ session $\times$ group $-\mathrm{F}_{28,378}=2.4$; all $p$-values $<0.0001$ ). In contrast, compared to baseline values, responses on the water lever (data not shown) were slightly, but not significantly, reduced during these sessions of re-exposure (responses/session on the water lever during the first session of re-exposure after the second and third deprivations were $10 \pm 3$ and $8 \pm 3$, respectively).

Examining responses on the ETOH lever individually for the second and third re-exposure cycles was employed to decompose the significant three-way interaction term. Focusing on the second re-exposure cycle, there was a significant effect of session $\left(\mathrm{F}_{7,189}=114.6 ; p<0.0001\right)$ and a session $\times$ group interaction $\left(\mathrm{F}_{14,189}=2.2 ; p=0.008\right)$, but no effect of group. During the second re-exposure cycle (Figure 2), responding on the ETOH lever by the 2- or 8week groups was elevated compared to baseline responding for sessions $1-3$ of re-exposure $\left(\mathrm{F}^{\prime} \mathrm{s}_{7,63}>50.7 ; p\right.$ 's $\left.<0.0001\right)$. For the 5-week group, responding on the ETOH lever was elevated compared to baseline responding for sessions 1-4 of re-exposure $\left(\mathrm{F}_{7,189}=41.6 ; p<0.0001\right)$. The reinforcements obtained on the first re-exposure session by the 2-, 5and 8-week deprived groups were increased from $58 \pm 4$, $52 \pm 3$ and $57 \pm 4$ to $118 \pm 6,113 \pm 6$ and $109 \pm 5$, respectively, following deprivation.

An analysis performed on the responses on the ETOH lever during the third re-exposure cycle indicated a significant effect of session $\left(\mathrm{F}_{7,189}=148.5 ; p<0.0001\right)$, but no session $\times$ group interaction $\left(\mathrm{F}_{14,189}=0.89 ; p=0.57\right)$, or effect of group $\left(\mathrm{F}_{2,27}=0.4 ; p=0.69\right)$. In all the three deprived groups (Figure 2), responding on the ETOH lever was elevated for sessions 1-5 of re-exposure compared to baseline levels $\left(\mathrm{F}^{\prime} \mathrm{s}_{7,63}>47.8\right.$; $p$ 's $\left.<0.0001\right)$. The reinforcements obtained on the first re-exposure session by the 2-, 5, and 8-week-deprived groups were increased from $60 \pm 3$, $54 \pm 3$, and $58 \pm 3$ to $144 \pm 9,157 \pm 9$, and $143 \pm 7$, respectively, following deprivation.

To further examine the effects of repeated deprivations on responses on the ETOH lever, for each group a repeated measure ('cycle' and 'session') ANOVA was performed separately. For each group (2-, 5-, and 8-week), there was a significant effect of cycle $\left(\mathrm{F}^{\prime} \mathrm{s}_{2,18}>71.3 ; p<0.0001\right)$, session $\left(\mathrm{F}^{\prime} \mathrm{s}_{7,63}>75.48 ; p<0.0001\right)$, and session $\times$ cycle interaction $\left(\mathrm{F}^{\prime} \mathrm{s}_{14,126}=27.5 ; p<0.0001\right)$. For all groups, exposure to repeated deprivations produced a step-wise increase $\left(\mathrm{F}^{\prime} \mathrm{s}_{2,19}>14.89 ; p\right.$ 's $\left.<0.0001\right)$ in responding on the $\mathrm{ETOH}$ lever (Figure 2). For the 2- and 8-week groups, responses on the ETOH lever during sessions 1-3 of re-exposure were greater after the second deprivation than the first depriva- 
tion, and responses after the third deprivation were elevated compared to responses following both the first and second deprivations for sessions 1-5 of re-exposure (Figure 2). Similarly, for the 5-week group, responses on the ETOH lever after the second and third deprivation were elevated compared to responses following the first deprivation during sessions 1-4 of re-exposure, and ethanol lever responses were greater following the third deprivation compared to responses following the first and second deprivations for sessions 1-5 of re-exposure.

\section{Cumulative Responses on the ETOH Lever in Session 1 After Repeated Deprivations}

An examination of the cumulative responses on the ETOH lever revealed that there were no significant changes in the response pattern during the last session prior to deprivation (all $p$ 's $>0.28$ ). Under baseline conditions, approximately $90 \%$ of the responses on the ETOH lever occurred within the first $20 \mathrm{~min}$ (Figure 3 shows data for the 5- and 8-week groups; data for the 2-week group are not shown but are similar to the 5-week group). A comparison of the cumulative response pattern (mixed factor ANOVA)

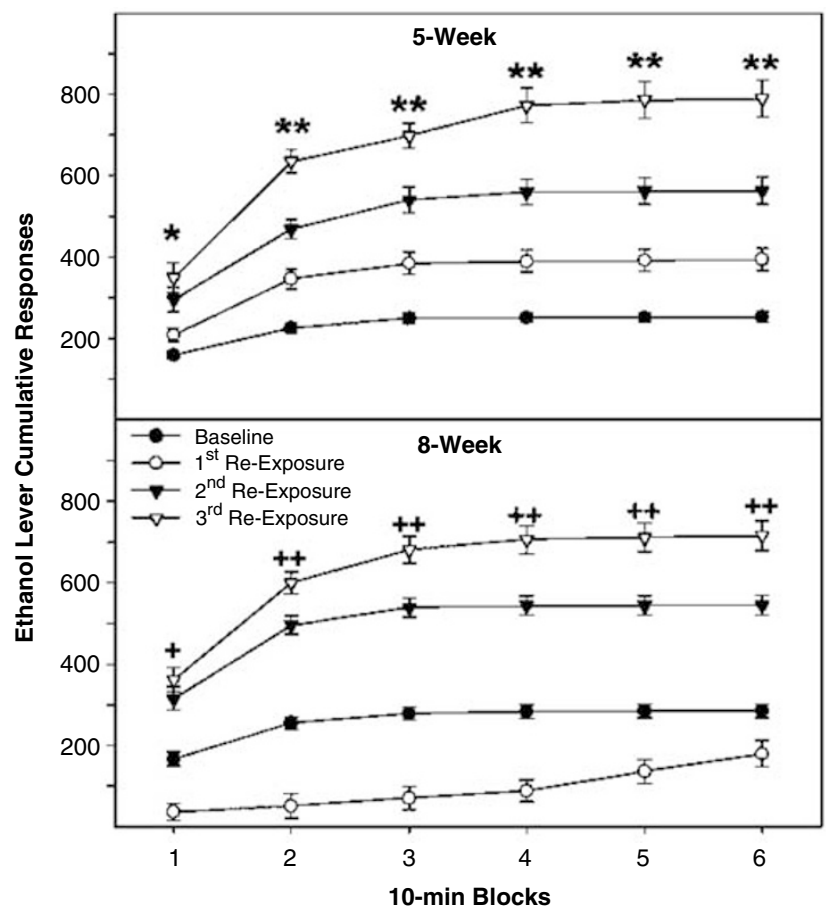

Figure 3 The mean ( \pm SEM) cumulative responses (in 10-min blocks) on the ethanol lever in the first session after each re-exposure for $P$ rats initially deprived for 5 or 8 weeks ( $n=10 /$ group), and then subjected to two additional cycles of 2 weeks of ethanol access and 2 weeks of deprivation (second and third re-exposures). Data for the 2-week group are not shown but are similar to data for the 5-week group. Baseline values are the average responses for each rat on the last 3 days prior to the initial deprivation. ${ }^{*} p<0.05$ (values for all three re-exposures greater than baseline and values for second and third re-exposures greater than first reexposure); ${ }^{+} p<0.05$ (values for the second and third re-exposure periods greater than baseline, also values for the first re-exposure less than baseline); ** $p<0.05$ (values for all re-exposures greater than baseline and different from each other); ${ }^{+}+p<0.05$ (values for the second and third reexposure periods greater than baseline and different from each other, also values for the first re-exposure less than baseline). between the average of the three baseline patterns contrasted with the three initial re-exposure sessions for each group indicated a significant effect of cycle $\left(\mathrm{F}_{3,81}=209.5 ; p<0.0001\right)$, time $\left(\mathrm{F}_{5,135}=82.3 ; p<0.0001\right)$, time $\times$ group $\times$ cycle interaction $\left(\mathrm{F}_{30,405}=1.6 ; p=0.03\right)$. The significant interaction term was primarily the result of the unique pattern of responding displayed by rats initially deprived for 8 weeks during the first session of reexposure. In contrast to the 2- and 5-week groups (Figure 3, top panel shows 5-week group), rats in the 8-week group, after the first deprivation (Figure 3, bottom panel), showed lower responding on the ETOH lever compared to baseline values throughout the session; responses on the ETOH lever began to recover toward baseline in the 50th $\mathrm{min}$. In contrast, the 2- and 5-week groups showed higher responding than baseline in the first $10 \mathrm{~min}$, which continued to increase in the second 10 -min segment. Following the second and third deprivations, rats in the 2and 5-week groups showed similar levels of responding on the ETOH lever in the first 10-min block, which were significantly higher than responding after the first deprivation. However, compared to the second deprivation, the third deprivation produced an additional significant increase in responding on the ETOH lever during the second 10-min block; there was a trend for this increase to continue up to the 4th 10-min block (Figure 3, top panel). The 8-week group also showed similar differences between the third and second deprivations in the pattern of responding on the ETOH lever with higher responding on the ETOH lever following the third than second deprivation starting with the second 10-min block (Figure 3, bottom panel).

\section{Progressive Ratio}

After the fourth deprivation, a progressive ratio session was undertaken to determine if repeated deprivation cycles altered breakpoint values (Figure 4). During the last session prior to the fourth deprivation, or in the nondeprived animals the last session prior to progressive ratio testing, the responses/session on the ETOH lever were between $254 \pm 24$ and $280 \pm 20$, whereas responses/session on the water lever were between $17 \pm 5$ and $23 \pm 5$. There was a significant effect of group for both the breakpoint value and the total number of responses on the ETOH lever during the progressive ratio session $\left(\mathrm{F}^{\prime} \mathrm{s}_{3,36}>17.3\right.$; $p$ 's $\left.<0.0001\right)$. Post hoc comparisons revealed that rats given repeated deprivations had a two-fold higher breakpoints values (FR values 30-32 for deprived groups $v s 15$ for the nondeprived group) and four-fold higher ETOH lever responses than the nondeprived group (700-900 responses for deprived groups vs 200 responses for nondeprived group). The number of reinforcements received during the progressive ratio test for nondeprived rats was $24 \pm 2$. Thus, nondeprived rats received approximately half the number of reinforcements normally received under an FR-5 schedule of reinforcement. Therefore, the current progressive ratio procedure has some form of internal validity since nondeprived rats ceased to work prior to satiety, a hallmark of progressive ratio tests (Hodos, 1961; Roberts et al, 1989). Similarly, the reinforcements/session attained by the deprived groups were approximately $30 \%$ of the reinforcements/session attained during the initial re-exposure session following the third 


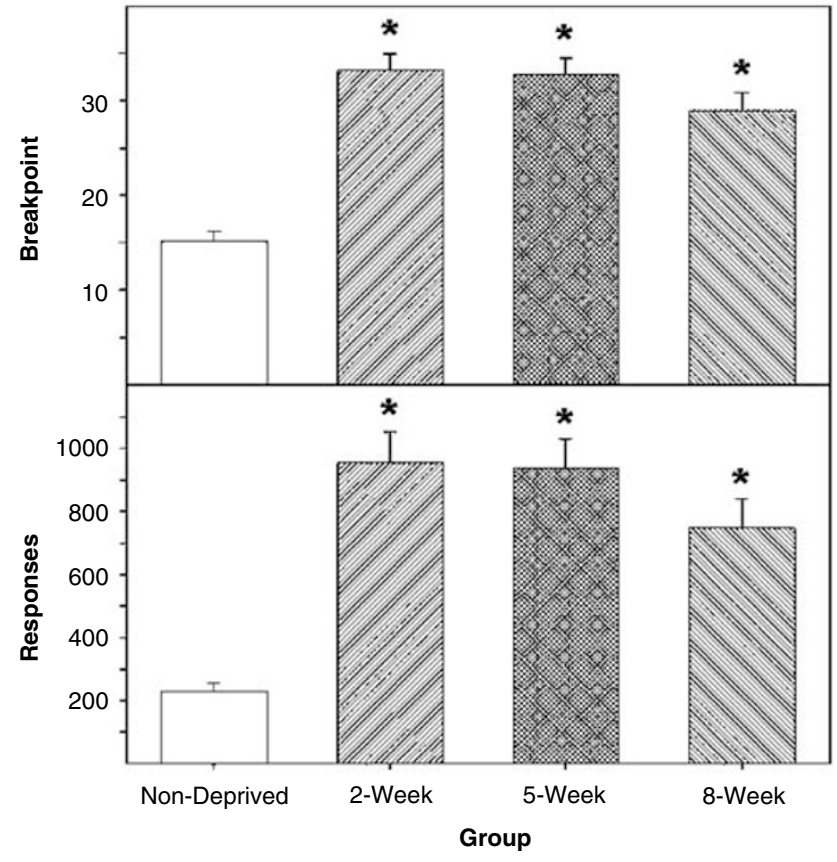

Figure 4 The mean ( \pm SEM) breakpoint values and total responses on he ethanol lever during the progressive ratio session after the fourth deprivation by $\mathrm{P}$ rats in the nondeprived group and in the three deprived groups (2-, 5- and 8-week initial deprivation). The breakpoint is the lowest fixed-ratio (FR) requirement that the $P$ rat did not meet. $* p<0.05$ (values for all three deprived groups greater than the nondeprived group)

deprivation period (2-week group- $51 \pm 3$; 5-week group - $50 \pm 4$; 8-week group - $44 \pm 5$ dipper presentation/session). Water responding (data not shown) was slightly elevated in all groups during the progressive ratio test (range 34 $\pm 7-44 \pm 8$ ), but there was no difference between groups. In general, water responses increased later in the progressive ratio session as the number of responses required to obtain a reinforcer of ETOH increased.

\section{DISCUSSION}

The major findings of the present study are that repeated alcohol deprivations increased the magnitude and the duration of responding on the ETOH lever (Figure 2), and that $\mathrm{P}$ rats repeatedly deprived of ETOH had a higher breakpoint ratio than rats given uninterrupted access to ETOH (FR values of 30-32 for deprived groups $v s 15$ for nondeprived; see Figure 4). These results support our hypothesis and suggest that repeated deprivations can increase the reinforcing effects of ETOH in the P rat.

The progressive ratio test is a quantitative measure of the amount of work a subject will perform to obtain a reinforcement (Hodos, 1961). The strength, or saliency, of a reinforcer is inferred by the amount of work a subject will perform until a point (breakpoint) where the work effort is not matched by the intrinsic reward of the reinforcer and the animal terminates responding (Hodos, 1961). Therefore, the two-fold higher breakpoint values for the deprived groups compared to the nondeprived group (Figure 4) suggest that the reinforcing strength of ETOH has increased with repeated deprivations. This effect is not merely a result of ETOH exposure alone because the nondeprived and the 5-week group had the same number of operant sessions and exposure to ETOH. However, the 5-week deprived group had 2-week periods of abstinence followed by several sessions of two- to three-fold higher ETOH intakes (Figure 2). It could be that the combination of prolonged deprivation followed by sessions of high alcohol intake is producing neuronal alterations that strengthen the reinforcing effects of ETOH. Additionally, the validity of the modified progressive ratio employed is supported in that both nondeprived and repeatedly deprived rats received about half the number of reinforcers typically earned during a regular fixed-ratio operant session. However, interpretation of the current progressive ratio data must be tempered by the fact that only a single concentration of ETOH was used during progressive ratio testing. To assess completely the reinforcing properties of ETOH in nondeprived and repeatedly deprived rats, an ETOH dose-response experiment would need to be conducted (Hodos, 1961; Roberts et al, 1989).

In contrast to the amount of research employing progressive ratio paradigms on other drugs of abuse, for example, cocaine, amphetamine, and morphine (Roberts et al, 1989; Covington and Miczek, 2001), there has been limited use of this technique in the study of alcohol. One of the reasons is that ETOH can produce sedation, whereas the other drugs of abuse are more stimulating. A second reason is that most rats will not demonstrate robust operant responding for ETOH. The P rat has been selectively bred for high alcohol-drinking behavior and will readily selfadminister ETOH under operant conditions with little or no prior training (Rodd-Henricks et al, 2002a, b). In Lister rats, which had repeated training with progressive ratio testing, withdrawal from an ethanol diet $(11 \mathrm{~g} / \mathrm{kg} /$ day $)$ increased the breakpoint determinant (Brown et al, 1998). Recently, P rats maintained on an FR-1 schedule of reinforcement for $10 \%$ $\mathrm{v} / \mathrm{v}$ ETOH and trained to lever press using the saccharinfade procedure displayed a higher breakpoint determinant than comparably trained alcohol nonpreferring (NP) rats (Ciccocioppo et al, 2001), although the number of reinforcements/session obtained by both the $\mathrm{P}$ and the NP rat was relatively low (approximately 18 and 8 , respectively). With the current procedure, the $\mathrm{P}$ rat received a higher number of reinforcements at baseline (48 \pm 4 reinforcements/session) and repeated deprivations significantly increased the number of reinforcements $(157 \pm 9$ reinforcements/session).

The presence of an ADE under operant conditions has been previously reported. In nonselected Wistar rats, a modest increase (60 responses/session; FR1 schedule of reinforcement) in responding was observed following a single deprivation period of between 5 and 28 days (Heyser et al, 1997). Additionally, Heyser et al (1998) reported that chronic acamprosate treatment $(200 \mathrm{mg} / \mathrm{kg} /$ day for 5 days $)$ inhibited responding on the $\mathrm{ETOH}$ lever during ADE testing. Furthermore, an ADE-like phenomenon was observed in ETOH vapor-exposed rats that were abstinent for 2- or 4-weeks and repeatedly withdrawn (Roberts et al, 2000). Previously, an operant ADE in P rats was observed following a deprivation of 2 weeks (McKinzie et al, 1998; Rodd-Henricks et al, 2002a,b). In the current study, an initial ADE was observed in P rats that were deprived 2 or 5 weeks, but not 8 weeks. However, the failure of the 8-week 
group to express an $\mathrm{ADE}$ during the initial re-exposure period may be the result of the rats in this group forgetting the operant paradigm. In support of this interpretation, with a 24-h free-choice alcohol drinking paradigm, $\mathrm{P}$ rats initially deprived of alcohol for 8 weeks demonstrated a similar ADE as those deprived for 2, 4 or 6 weeks (RoddHenricks et al, 2000b), suggesting that similar neuronal alterations associated with expression of the ADE have occurred in all four groups. An examination of the cumulative responses in the 8 -week group indicates that during the first $30 \mathrm{~min}$ period of the initial re-exposure session (Figure 3), rats responded at a rate four-fold less than the baseline response rate. Thus, in rats that had only a limited amount of exposure to oral, operant self-administration of ethanol ( 6 weeks), a deprivation period of 8 weeks may result in extinction, which may require the animals to reacquire operant responding behaviors. The data also indicate that regardless of the lack of expression of an ADE during the first re-exposure cycle, rats initially deprived for 8 weeks responded at the heightened level seen in the other groups following the second and third deprivations (Figure 2).

An increase in both the magnitude and duration of the ADE was observed for $\mathrm{P}$ rats under $24-\mathrm{h}$ continuous access conditions with repeated deprivations when multiple ETOH concentrations were concurrently available (Rodd-Henricks et al, 2001), but only an increase in the duration of the ADE was observed with repeated deprivations when a single ETOH concentration was available (Rodd-Henricks et al, 2000b). Repeated deprivations have not previously been conducted with limited access paradigms with or without the use of operant techniques. Therefore, the results of the present study using a single ETOH concentration and an operant paradigm resemble the data for the repeated deprivations with access to multiple ETOH concentrations, because both the magnitude and the duration of the ADE were increased with repeated deprivations. These results suggest that there might be an interaction between repeated deprivations and the operant procedure even when only a single ETOH concentration is given.

Fluid intakes were not measured in the present experiment but were measured in a separate experiment to ensure that there was a relation between the number of reinforcements presented and the amount of $15 \%$ ETOH consumed. Under similar operant conditions, it was determined that $\mathrm{P}$ rats actually consume $97 \%$ of the amount estimated on the basis of the number of reinforcements. Therefore, in nondeprived $\mathrm{P}$ rats, an estimate of the amount of ETOH consumed was between 4.6 and $5.4 \mathrm{ml}$. Given that the average weight of the rat was $475 \mathrm{~g}$, the amount of ETOH consumed by nondeprived rats was equivalent to $1.2-4 \mathrm{~g} / \mathrm{kg}$. In contrast, in rats initially deprived for 5 weeks, during the initial re-exposure period, the estimated amount of ETOH consumed was $7.7 \mathrm{ml}$, which would result in ETOH intakes of $1.9 \mathrm{~g} / \mathrm{kg}$. However, during the initial re-exposure session following the second deprivation period, rats in the 5-week group consumed $10.9 \mathrm{ml}$ of $15 \% \mathrm{ETOH}$, which resulted in an average ETOH intake of $2.7 \mathrm{~g} / \mathrm{kg}$. Following the third deprivation period, rats initially deprived for 5 weeks consumed $15.3 \mathrm{ml}$, which resulted in an average ETOH intake of $3.8 \mathrm{~g} / \mathrm{kg}$. ETOH intakes by $\mathrm{P}$ rats under $1-\mathrm{h}$ limited access conditions were $1.3 \mathrm{~g} / \mathrm{kg}$ and equivalent to the amount consumed by $\mathrm{P}$ rats in the present operant studies; this intake produced blood alcohol concentrations of $76 \pm 13 \mathrm{mg} \%$ (Murphy et al, 1986). Therefore, blood alcohol concentrations following the third deprivation could be approaching $200 \mathrm{mg} \%$. The higher amounts of ETOH consumed (which produce higher blood alcohol concentrations) may indicate that tolerance to the high dose effects of ETOH has developed with repeated deprivations.

The $\mathrm{P}$ rats in the current experiment did not have sufficient alcohol exposure to establish physical dependence (Waller et al (1982); no overt withdrawal symptoms were noted in any of the rats during the current experiment). However, repeated alcohol withdrawals have been postulated to increase the vulnerability and susceptibility of future withdrawal episodes (Becker et al, 1997). Thus it is possible that, in genetically vulnerable populations such as the $\mathrm{P}$ rat, neurobiological adaptations may occur with repeated cycles of alcohol drinking and abstinence which enhance the rewarding effects of ETOH. In agreement with the present results on the effects of repeated cycles of ETOH drinking and deprivation, a recent report indicated that multiple previous detoxifications were associated with reduced response to treatment of withdrawal symptoms and heavier drinking during outpatient detoxification (Malcolm et al, 2000).

In conclusion, the $\mathrm{ADE}$ has been posited as an animal model of alcohol craving and may be akin to binge drinking in humans (Heyser et al, 1997). In the current experiment employing a repeated alcohol deprivation paradigm, $\mathrm{P}$ rats upon re-exposure displayed a pronounced level of ETOH responding, and hence intake, for up to 5 days, and increased the amount of work they were willing to perform to obtain access to ETOH. Thus, repeated deprivations invoked a drinking pattern in $\mathrm{P}$ rats very similar to that of binge drinking observed in human alcoholics (Finney and Moos, 1991; Nezlek et al, 1994), and may have enhanced the reinforcing properties of ETOH in this selectively bred line of rats. Therefore, repeated alcohol deprivations, which more closely model the human alcohol-drinking pattern (McMillen, 1997), may be more valid than the singledeprivation $\mathrm{ADE}$ procedure for studying relapse/craving and 'binge' drinking. Further work on the neural mechanisms of the $\mathrm{ADE}$ is needed, which may ultimately lead to advances in efficacious treatments to prevent relapse of alcohol drinking in humans.

\section{ACKNOWLEDGEMENTS}

This study was supported in part by NIAAA Grants AA07462, AA07611, AA10721, and AA11261.

\section{REFERENCES}

Agabio R, Carai MAM, Lobina C, Pani M, Reali R, Vacca G et al (2000). Development of short-lasting alcohol deprivation effect in Sardinian alcohol-preferring rats. Alcohol 21: 59-62.

Becker HC, Diaz-Granados JL, Weathersby RT (1997). Repeated ethanol withdrawal increases the severity and duration of subsequent withdrawal seizures in mice. Alcohol 14: 319-326.

Brown G, Jackson A, Stephens DN (1998). Effects of repeated withdrawal from chronic ethanol on oral self-administration of 
ethanol on a progressive ratio schedule. Behav Pharmacol 9: 149-161.

Burish TG, Maisto SA, Cooper AM, Sobell MB (1981). Effects of voluntary short-term abstinence from alcohol on subsequent drinking patterns of college students. J Stud Alcohol 42: 1013-1020.

Ciccocioppo R, Angeletti S, Weiss F (2001). Long-lasting resistance to extinction of response reinstatement induced by ethanolrelated stimuli: role of genetic ethanol preference. Alcohol Clin Exp Res 25: 1414-1419.

Cicero TJ (1979). A critique of animal analogs of alcoholism. In: Majchrowich E, Noble EP (eds) Biochemistry and Pharmacology of Ethanol, Vol. 2, pp 533-560, Plenum Press: New York.

Covington III HE, Miczek KA (2001). Repeated social-defeat stress, cocaine or morphine: effects on behavioral sensitization and intravenous cocaine self-administration "binges". Psychopharmacology 158: 388-398.

Finney JW, Moos RH (1991). The long-term course of treated alcoholism: I. Mortality, relapse and remission rates and comparisons with community controls. J Stud Alcohol 52: 44-54.

Heyser CJ, Schulteis G, Durbin P, Koob GF (1998). Chronic acamprosate eliminates the alcohol deprivation effect while having limited effects on baseline responding for ethanol in rats. Neuropsychopharmacology 18: 125-133.

Heyser CJ, Schulteis G, Koob GF (1997). Increased ethanol selfadministration after a period of imposed ethanol deprivation in rats trained in a limited access paradigm. Alcohol Clin Exp Res 21: 784-791.

Hilbrom ME (1990). Alcohol withdrawal seizures and binge vs chronic drinking. In: Port RJ, Mattson RH, Cramer JA, Diamond I (eds) Alcohol and Seizures: Basic Mechanisms and Clinical Concepts, pp 206-215, FA Davis: Philadelphia.

Hodos W (1961). Progressive ratio as a measure of reward strength. Science 134: 943-944.

Kornet M, Goosen C, Van Ree JM (1991). Effect of naltrexone on alcohol consumption during chronic alcohol drinking and after a period of imposed abstinence in free-choice drinking rhesus monkeys. Psychopharmacology 104: 367-376.

Malcolm R, Roberts JS, Wang W, Myrick H, Anton RF (2000). Multiple previous detoxifications are associated with less responsive treatment and heavier drinking during an index outpatient detoxification. Alcohol 22: 159-164.

McBride WJ, Li T-K (1998). Animal models of alcoholism: neurobiology of high alcohol-drinking behavior in rodents. Crit Rev Neurobiol 12: 339-369.

McKinzie DL, Nowak KL, Yorger L, McBride WJ, Murphy JM, Lumeng $\mathrm{L}$ et al (1998). The alcohol deprivation effect in the alcohol-preferring $\mathrm{P}$ rat under free-drinking and operant access conditions. Alcohol Clin Exp Res 22: 1170-1176.

McMillen BA (1997). Toward a definition of a valid animal model of alcoholism: multiple animal models for multiple diseases. Alcohol 14: 409-419.

Murphy JM, Gatto GJ, Waller MB, McBride WJ, Lumeng L, Li T-K (1986). Effects of schedule access on ethanol intake by the alcohol-preferring $\mathrm{P}$ line of rats. Alcohol 3: 331-336.
Murphy JM, Stewart RB, Bell RL, Badia-Elder NE, Carr LG, McBride WJ et al (2002). Phenotypic and genotypic characterization of the Indiana University rat lines selectively bred for high and low alcohol preference. Behav Genet 32: 363-388.

Nezlek JB, Pilkington CJ, Bilbro KG (1994). Moderation in excess: binge drinking and social interaction among college students. $J$ Stud Alcohol 55: 342-351.

Roberts AJ, Heyser CJ, Cole M, Griffin P, Koob GF (2000). Excessive ethanol drinking following a history of dependence: animal model of allostasis. Neuropsychopharmacology 22: 581-594.

Roberts DCS, Bennett SAL, Vickers G (1989). Self-administration of cocaine on a progressive ratio schedule in rats: dose-response relationship and effect of haloperidol pretreatment. Psychopharmacology 97: 535-538.

Rodd-Henricks ZA, Bell RL, Kuc KA, Murphy JM, McBride WJ, Lumeng $L$ et al (2001). Effects of concurrent access to multiple ethanol concentrations and repeated deprivations on alcohol intake of alcohol-preferring rats. Alcohol Clin Exp Res 25: $1140-1150$.

Rodd-Henricks ZA, Bell RL, Kuc KA, Murphy JM, McBride WJ, Lumeng $\mathrm{L}$ et al (2002a). Effects of ethanol exposure on subsequent acquisition and extinction of ethanol self-administration and expression of alcohol-seeking behavior in adult alcohol-preferring (P) rats. I. Periadolescent exposure. Alcohol Clin Exp Res 26: 1632-1641.

Rodd-Henricks ZA, Bell RL, Kuc KA, Murphy JM, McBride WJ, Lumeng $\mathrm{L}$ et al (2002b). Effects of ethanol exposure on subsequent acquisition and extinction of ethanol self-administration and expression of alcohol-seeking behavior in adult alcohol-preferring (P) rats. II. Adult exposure. Alcohol Clin Exp Res 26: 1642-1652.

Rodd-Henricks ZA, McKinzie DL, Murphy JM, McBride WJ, Lumeng L, Li T-K (2000a). The expression of an alcohol deprivation effect in the high-alcohol-drinking replicate rat lines is dependent on repeated deprivations. Alcohol Clin Exp Res 24: 747-753.

Rodd-Henricks ZA, McKinzie DL, Shaikh SR, Murphy JM, McBride WJ, Lumeng $\mathrm{L}$ et al (2000b). Alcohol deprivation effect is prolonged in the alcohol preferring $(\mathrm{P})$ rat after repeated deprivations. Alcohol Clin Exp Res 24: 8-16.

Sinclair JD, Li T-K (1989). Long and short alcohol deprivation: effects on AA and P alcohol-preferring rats. Alcohol 6: 505-509.

Sinclair JD, Senter RJ (1967). Increased preference for ethanol in rats following deprivation. Psychon Sci 8: 11-12.

Sinclair JD, Senter RJ (1968). Development of an alcoholdeprivation effect in rats. Q J Stud Alcohol 29: 863-867.

Sinclair JD, Tiihonen K (1988). Lack of alcohol-deprivation effect in AA rats. Alcohol 5: 85-87.

Spanagel R, Zieglgansberger W (1997). Anti-craving compounds for ethanol: new pharmacological tools to study addictive processes. Trends Pharmacol Sci 18: 54-59.

Waller MB, McBride WJ, Lumeng L, Li T-K (1982). Induction of dependence on ethanol by free-choice drinking in alcoholpreferring rats. Pharmacol Biochem Behav 16: 501-507. 